\title{
Habilidades Matemáticas na Base Nacional Comum Curricular: Vislumbrando Caminhos Analíticos
}

\section{Mathematical Skills in the National Curricular Common Base: Envisioning Analytical Paths}

\author{
Marcelo de Oliveira Dias*ab; Jonei Cerqueira Barbosa ${ }^{\text {cd }}$
}

\begin{abstract}
aUniversidade Federal Fluminense, Instituto do Noroeste Fluminense de Educação Superior, Programa de Pós-Graduação Stricto Sensu em Ensino. RJ, Brasil.
${ }^{\mathrm{b}}$ Universidade Federal Fluminense, Programa de Pós-Graduação em Ensino de Ciências em Matemática. RJ, Brasil.

${ }^{\mathrm{C}}$ Universidade Federal da Bahia, Programa de Pós-Graduação Stricto Sensu em Educação.BA, Brasil.

${ }^{d}$ Universidade Federal da Bahia, Programa de Pós-Graduação Stricto Sensu em Ensino de Ciências, Filosofia e História das Ciências. BA, Brasil. *E-mail: marcelo_dias@id.uff.br
\end{abstract}

\begin{abstract}
Resumo
No artigo em tela, objetivou-se a análise da Base Nacional Comum Curricular (BNCC), na área Matemática, que emergiu no Brasil e foi consolidada após um processo de consultas públicas e debates. Os aportes teóricos adotados para a análise foram Bishop (1999), que propôs competências matemáticas básicas para a formação do cidadão, Doll (1997), que sugeriu alguns critérios para a organização do currículo, e Silva (2009), que o ampliou em outros critérios, dividindo-os em dois grandes blocos, sendo o primeiro relacionado à seleção dos conteúdos, e o segundo relacionado à organização curricular. Os referenciais foram adotados para a análise da coerência da prescrição para os Anos Finais do Ensino Fundamental, relacionando seus indícios e suas conexões com o quadro preliminar do Projeto Matemática 2030, que visa, dentre outras coisas, estabelecer critérios para a análise dos programas destinados às futuras gerações de alunos. Os critérios e suas conexões auxiliam na compreensão de tendências e impactos de reformas nos documentos prescritos para Matemática no Brasil e em outros países. Os resultados suscitaram uma visão multicultural restrita às unidades Álgebra e Probabilidade e Estatística ao relacionarem os objetos de conhecimento à percepção do sentido dos conteúdos para uso social e acesso à cidadania.
\end{abstract}

Palavras-chave: Base Nacional Comum Curricular. Habilidades. Critérios de Análise. Anos Finais do Ensino Fundamental. Matemática.

\begin{abstract}
The objective of this paper is to analyze the National Curricular Common Base (NCCB), Mathematical area, which emerges in Brazil and was consolidated after a process of public consultations and debates. The theoretical contributions adopted for the analysis were Bishop, who proposes basic mathematical skills for the formation of the citizen, Doll, that suggests criteria for the organization of the curriculum, and Silva, that expands in others, dividing them into two large blocks, being the first related to the selection of contents and the other to the curricular organization. The references were adopted for the analysis of the consistency of the prescription for the Final Years of Elementary Teaching, relating their indications and their connections with the preliminary framework of the Mathematics 2030 Project, which aims, among other things, to establish criteria for the analysis of the programs destined to future generations of students. The criteria and their connections help in understanding the trends and impacts of reforms in the documents prescribed for Mathematics in Brazil and in other countries. The results gave rise to a multicultural view restricted to the units Algebra and Probability and Statistics, relating the objects of knowledge to the perception of the meaning of the contents for social use and access to citizenship.
\end{abstract}

Keywords: National Curricular Common Core. Skills. Criteria of Analysis. Final Years of Elementary School. Mathematics.

\section{Introdução}

O currículo é definido por Sacristán (2000) como um projeto seletivo cultural, social, política e administrativamente condicionado que preenche a atividade escolar e que se torna realidade dentro das condições da escola tal como se acha configurada. A partir daí, considera-se que "em um currículo se entrecruzam componentes e determinações muito diversas: pedagógicas, políticas, práticas administrativas, produtivas de diversos materiais, de controle sobre o sistema escolar, de inovações pedagógicas, etc.” (p. 32). Assim, um currículo não pode ser entendido à parte do contexto no qual se configura e independentemente das condições em que se desenvolve, caracterizando-se como um objeto social e histórico. Em relação ao currículo prescrito:

Em todo sistema educativo, como consequência das regulações inexoráveis às quais está submetido, levando em conta sua significação social, existe algum tipo de prescrição ou orientação do que deve ser seu conteúdo, principalmente em relação à escolaridade obrigatória. São aspectos que atuam como referência na ordenação do sistema curricular, servem de ponto de partida para a elaboração de materiais, controle do sistema, etc. (p. 104).

Neste artigo, apropriar-se-á dessa definição, considerando a Base Nacional Comum Curricular (BNCC) como currículo prescrito por se configurar como documento oficial publicado pelo Governo Federal, o qual prescreve conteúdos obrigatórios, ordenados pelo Estado como forma de intervir na cultura e na ordenação social e econômica da sociedade. Nesse sentido, a BNCC, primeiro ordenamento obrigatório curricular no país, anuncia em sua prescrição que sua implementação visa também "superar a fragmentação das políticas educacionais, 
enseje o fortalecimento do regime de colaboração entre as três esferas de governo e seja balizadora da qualidade da educação, isto é, da garantia do direito dos alunos a aprender e a se desenvolver, contribuindo para o desenvolvimento pleno da cidadania" (Brasil, 2017, p.8).

O desenvolvimento da cidadania também é enfatizado na sexta competência geral do documento para o Ensino Fundamental, que deve se propor a:

Valorizar a diversidade de saberes e vivências culturais e apropriar-se de conhecimentos e experiências que lhe possibilitem entender as relações próprias do mundo do trabalho e fazer escolhas alinhadas ao exercício da cidadania e ao seu projeto de vida, com liberdade, autonomia, consciência crítica e responsabilidade (Brasil, 2017, p. 9).

A BNCC indica que as decisões pedagógicas devem estar orientadas para o desenvolvimento de competências para o exercício da cidadania e, especificamente para os Anos Finais do Ensino Fundamental, que:

A compreensão dos estudantes como sujeitos com histórias e saberes construídos nas interações com outras pessoas, tanto do entorno social mais próximo quanto do universo da cultura midiática e digital, fortalece o potencial da escola como espaço formador e orientador para a cidadania consciente, crítica e participativa (Brasil, 2017, p. 60).

Dessa forma, questiona-se: Quais direções são possíveis para a análise dos conhecimentos, habilidades e competências que valorizem a diversidade de saberes, a cultura e o exercício da cidadania prescritas na BNCC para os Anos Finais do Ensino Fundamental?

Neste artigo refletir-se-á a respeito de algumas contribuições teóricas contemporâneas no âmbito do campo de pesquisa sobre currículo, trazendo possíveis critérios para a análise da BNCC, área Matemática, que emerge no país.

\section{A Base Nacional Comum Curricular: uma Breve Apresentação}

Dias (2016, p.39) alerta que "o pesquisador não pode prescindir de conhecer satisfatoriamente a conjuntura política que propiciou a produção de um determinado documento". Sendo assim, tratar-se-á de uma breve descrição dos aspectos legais, bem como da estrutura da $\mathrm{BNCC}^{2}$ prevista na Constituição para o Ensino Fundamental e ampliada no Plano Nacional de Educação (PNE) para o Ensino Médio, com o intuito de reelaborar e significar a educação básica no Brasil, sendo consideradas as duas noções fundantes da BNCC.

Com a homologação da BNCC, as redes de ensino e escolas particulares teriam, diante de si, a tarefa de construir currículos com base nas aprendizagens essenciais estabelecidas, passando, assim, do "[...] plano normativo propositivo para o plano da ação e da gestão curricular que envolve todo o conjunto de decisões e ações definidoras do currículo e de sua dinâmica" (Brasil, 2017, p.14). Nesse sentido, a Lei de Diretrizes e Bases da Educação Nacional, no inciso IV de seu art. 9. ${ }^{\circ}$, enfatiza que:

(...) cabe à União estabelecer, em colaboração com os Estados, o Distrito Federal e os Municípios, competências e diretrizes para a Educação Infantil, o Ensino Fundamental e o Ensino Médio, que nortearão os currículos e seus conteúdos mínimos, de modo a assegurar formação básica comum (Brasil, 1996 apud Brasil, 2017, p. 10).

Com base neste inciso, são destacados como claros dois conceitos decisivos para todo o desenvolvimento da questão curricular no Brasil, baseados em duas noções consideradas fundantes: o que é ou não básico-comum e as aprendizagens essenciais como foco.

O primeiro, já antecipado pela Constituição, estabelece a relação entre o que é básico-comum e o que é diverso em matéria curricular: as competências e diretrizes são comuns, os currículos são diversos. O segundo se refere ao foco. Ao dizer que os conteúdos curriculares estão a serviço do desenvolvimento de competências, orienta a definição das aprendizagens essenciais, e não apenas dos conteúdos mínimos a ser ensinados (Brasil, 2017, p. 11).

Para a elaboração da BNCC, foram formadas equipes autônomas. Na divulgação inicial, o Ministério da Educação (MEC) fez questão de sinalizar que, assim como o Conselho Nacional de Educação (CNE), o documento não expressava suas posições. Os nomes dos especialistas não foram divulgados no documento inicial, tampouco os critérios para a sua escolha, sendo apenas divulgada no Diário Oficial da União $^{3}$ (DOU) uma listagem geral com 112 especialistas, sendo cerca de 15 de Matemática. A falta de transparência e critérios de convocação foram bastante questionadas pela comunidade brasileira de Educação Matemática.

Após pouco tempo para apreciação e discussão, houve o envio de sugestões por meio de consulta pública no portal Movimento da Base, que seriam posteriormente analisadas, e a promoção de debates estaduais.

$\mathrm{O} \mathrm{MEC}$, antes da consolidação da BNCC, divulgou que a análise seria segundo os critérios de clareza, relevância e pertinência, e enviou ao CNE uma segunda versão da Base para nortear o ensino, a aprendizagem, a formação inicial e continuada de professores e o material didático a serem recomendados. Em abril de 2017, foi homologada e publicada a terceira e final versão da BNCC para os Anos Iniciais e Finais do Ensino Fundamental, para ser implementada no ano de 2019.

A seguir, na Figura 1, apresenta-se a estrutura do documento para a área de Matemática nesta etapa da escolaridade: 
Figura 1 - Estrutura da BNCC de Matemática para o Ensino Fundamental.

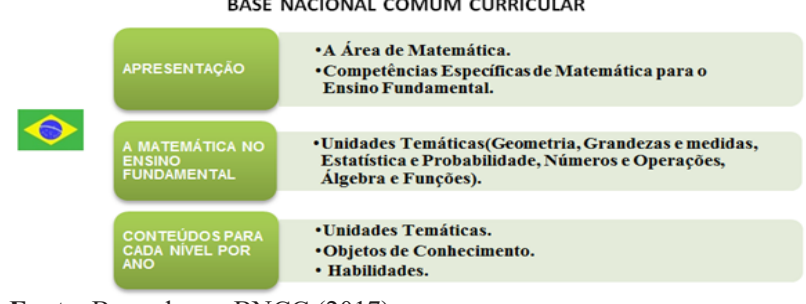

Fonte: Baseado em BNCC (2017).

Conforme ilustrado, pela BNCC, são propostas cinco unidades temáticas correlacionadas que orientam a formulação de habilidades a serem desenvolvidas ao longo do Ensino Fundamental. Neste documento, competência é definida como a "mobilização de conhecimentos (conceitos e procedimentos), habilidades (práticas, cognitivas e socioemocionais), atitudes e valores para resolver demandas complexas da vida cotidiana, do pleno exercício da cidadania e do mundo do trabalho" (Brasil, 2017, p. 13). Nesse sentido, objetos de conhecimento e habilidades prescritas representam os pontos chaves da proposta para o desenvolvimento de competências matemáticas essenciais.

\section{Revisão da Literatura}

Buscou-se na literatura pesquisas recentes que abordavam processos de reorganização curricular, prioritariamente, as que tratavam sobre reformas com foco em competências e suas finalidades. Foram considerados, também, seus impactos na organização de conhecimentos considerados prioritários, especificamente o matemático, no intuito de refletir sobre possíveis impactos no contexto educacional brasileiro a partir da BNCC, um documento estruturado por objetos de conhecimento, habilidades e competências.

Baeten \& Schneider (2012), bem como Volmink (2018), versaram, respectivamente, de reformas curriculares em Matemática na parte francesa da Bélgica e na África do Sul. Já os autores Clements et al. (2013) e Artigue (2018) abordaram tendências globais de reformas do currículo de Matemática.

Nos estudos de Baeten e Schneider (2012), focou-se na reorganização curricular em termos de competências e, assim como anunciado na BNCC, constatou-se que a reforma fazia parte de um plano de igualdade de oportunidades, integração social e educação para a cidadania, mas foi uma política de centralização e para maior controle do sistema.

$\mathrm{Na}$ pesquisa salienta-se que essa reforma na Bélgica foi acompanhada por uma padronização do currículo com a elaboração de quadros de competências para todos os níveis e criação de ferramentas de avaliação para servirem como referências externas comuns às redes de educação. A ênfase foi dada às competências transversais, válidas para todas as disciplinas. Em Matemática, particularmente, o foco foi em competências de resolução de problemas, descritas em termos muito gerais, sem considerar especificidades em domínios particulares.
Segundo Baeten \& Schneider (2012), a formulação de competências gerais foi mal coordenada com o conteúdo matemático que permaneceu quase o mesmo. Um relatório apontou inconsistências, descontinuidades, omissões e repetições, e que planejar o desenvolvimento progressivo de competências ainda era um grande desafio para a maioria dos professores. Isso sugeriu a definição, para cada disciplina, do conhecimento "prioritário" em detrimento do exercício de competências "realmente úteis" e que podem, razoavelmente, ser-consideradas fundamentais em uma cultura cidadã no campo disciplinar em jogo.

Volmink (2018), ao questionar se a reforma ocorrida na África do Sul foi coordenada para todos, concluiu que ela partiu de uma necessidade de desenvolver um currículo de Matemática que não só reconhecesse o desafio da competitividade global, fornecendo uma plataforma para desenvolver os conhecimentos, aptidões e competências para participar numa economia do século XXI. Entretanto, que também mostrasse como os nossos valores fundamentais podem ser vividos em nossa experiência cotidiana, ao mesmo tempo, iluminando e expondo violações destes valores.

A reforma curricular da Matemática mantém em tensão a necessidade de fornecer Matemática para todos, por um lado, enquanto cria oportunidades para assegurar que a realização Matemática seja vista e experimentada como parte do 'eu possível' de todo aprendiz (Volmink, 2018, p.108).

Clements et al. (2013, p.33) também alertaram que "precisamos ter certeza de que o tipo de Matemática que é apresentada nas propostas curriculares como adequada para todos é realmente adequada para todos".

Artigue (2018), na tentativa de realizar uma contribuição sobre desafios das reformas curriculares, concluiu que elas expressam visões bastante próximas do que nossas respectivas sociedades esperam da educação matemática. Tendências comuns são observadas, como a mudança para os currículos estruturados em torno de competências transversais aos domínios matemáticos, onde a importância está ligada em mostrar o papel da matemática para abordar as questões sociais e ambientais, ligação entre as disciplinas e as práticas interdisciplinares, o espaço crescente ao domínio estocástico, às atividades de modelagem e à atenção aos interesses e necessidades específicas dos alunos, as especificidades de cada contexto e a diversidade de dinâmicas curriculares que delas decorrem.

A partir dos estudos da literatura evidencia-se a importância da análise da reforma do currículo da matemática escolar no Brasil com a proposta da BNCC, uma vez que o documento expressa ideias de currículo organizado e sequenciado para uma coerência interna, trazendo a necessidade de reflexão sobre seus possíveis efeitos, as aprendizagens consideradas essenciais e globais (Volmink, 2018) e as possíveis relações com as matrizes de avaliações externas.

Esses estudos também reforçam a necessidade de uma lente crítica para verificar como vem sendo expressas nas 
reformas as noções de matemática (Clements et al., 2013), a passagem de domínios de competências gerais/transversais para competências matemáticas (Baeten \& Schneider, 2012; Volmink, 2018; Artigue, 2018), suscitando a necessidade, como é proposto no presente texto, da criação e reflexão contínua sobre possíveis critérios que possam ser relevantes para a análise de um documento oficial prescrito que priorize a formação plena de um cidadão mediante as demandas da sociedade global.

\subsection{Aportes Teóricos}

Nesta sessão, trazem-se alguns aportes teóricos que irão subsidiar as análises do estudo referente ao documento proposto em sua versão final, verificando se as concepções expressas na BNCC apresentam indícios de um currículo organizado que considere componentes essenciais expressos por esses autores para o desenvolvimento dos jovens no presente século.

Ao se questionar sobre as competências matemáticas básicas necessárias para formação do aluno para viver em sociedade e em diferentes contextos em nossa contemporaneidade, Bishop (1999) propõe que essa formação se dá consoante a alguns componentes: simbólico, social e cultural.

O componente simbólico destaca as ferramentas matemáticas essenciais em qualquer cultura para a aprendizagem, ou seja, baseado nos conceitos a serem apreendidos para viver em uma cultura. Organiza-se em torno de seis atividades universais presentes nas diferentes culturas: contar, localizar, medir, desenhar, jogar e explicar. Segundo Bishop (1999, p.132):

Não contemplando estes conceitos como "temas" no sentido de que eles são dados na revisão dos programas. Conceitos são oferecidos como organizadores do currículo que fornecem a estrutura do conhecimento.

Deveriam ser os centros de interesse e deveriam ser abordados por meio de atividades ricas realizadas em contextos relacionados com o meio ambiente, deveriam ser explorados pelo seu significado, sua lógica, e suas conexões com a matemática, e deveriam generalizar para outros contextos para ilustrar e validar seu poder explicativo.

Para o autor, o componente simbólico destaca os conceitos que vale a pena conhecer por meio de atividades relacionadas com contextos ricos para a aprendizagem do aluno.

O componente social transmite as ideias fundamentais sobre o poder do conhecimento matemático em um contexto social. Em vista disso, propõe-se que os alunos trabalhem em projetos, em especial, sobre as sociedades do passado, da atualidade e do futuro. Bishop (1999, p.140) considera que esses projetos:

Permitiriam a um professor desenvolver nos estudantes uma consciência do poder e as limitações da representação e da explicação matemática, e a importância relativa dos valores do controle e o progresso.

Dessa forma, aluno e professor têm papéis bem definidos no processo educacional ao serem propostos projetos para que se alcancem os conceitos estabelecidos pelo componente simbólico da Educação Matemática. O componente social impõe à aprendizagem pensar-se na perspectiva de como se utilizam as ideias matemáticas em situações sociais.

Já o componente cultural ocupa-se em ampliar o repertório do aluno em relação aos critérios internos da Matemática, conhecimento imprescindível em qualquer cultura. Assim,

Este componente pretende demonstrar a natureza da Matemática como cultura, o tipo de relação com as abstrações que matemáticos possuem e o fato de que as ideias matemáticas foram inventadas. (...). Portanto, é incluída em parte para iniciar os alunos no nível técnico da cultura Matemática, na medida em que seja possível fazer isso com os jovens aprendizes, de forma acessível (...) Em vez de buscar uma perspectiva "externa" da Matemática, aqui se preocuparemos muito mais com os critérios internos (Bishop, 1999, p. 149).

Para Bishop, o componente cultural sinaliza como, ou talvez por que, se geraram as ideias matemáticas e permite a reflexão sobre o que é a Matemática. O autor também enfatiza a necessidade de um equilíbrio entre esses três componentes do currículo. Para ele, as atividades relacionadas ao entorno, os projetos sobre as sociedades do passado, a atual e a do futuro, aspectos criativos da investigação, são importantes para a educação e formação das gerações futuras.

Assim, entende-se que conteúdos escolares devem ser significados e estão ligados ao desenvolvimento de atitudes, habilidades e competências. Nesse sentido, Silva (2009), sugere a seleção e organização dos conteúdos por meio de oito critérios, sendo quatro baseados nos aportes teóricos de Doll — riqueza, recursão, relações e rigor - e sugere outros quatro - reflexão, realidade, responsabilidade e ressignificação. Doll (1997, p.180) afirma que um currículo pós-moderno exigirá "ser rico em diversidade, problemática e heurística, assim como uma atmosfera da sala de aula que estimule a exploração - um passo além da descoberta. $\mathrm{O}$ autor propõe critérios para um currículo destinado a promover essa visão:

Que critérios poderíamos usar para avaliar a qualidade de um currículo pós-moderno - um currículo gerado, não pré-definido, indeterminado, mas limitado, explorando o "fascinante reino imaginativo da risada de Deus", e constituído por uma rede sempre crescente de "universidades locais"? Eu sugiro que os quatro Rs de Riqueza, Recursão, Relações e Rigor poderiam servir para este propósito (Doll, 1997, p.192).

Silva (2009) sugere uma reflexão mais profunda sobre os quatro R's de Doll aplicados à Educação Matemática, propondo-os como fundamentos iniciais para análise de conteúdos de Matemática. O autor destaca que o conceito pósmoderno de currículo e os parâmetros objetivos por meio dos quais Doll se posiciona. Assim, segundo Silva (2009, p.223225):

A "riqueza" privilegia a escolha de conteúdos que mostrem o quão rica a própria matemática é e como a relação teoria-prática pode ser dosada de maneira eficiente (...); (2) a "reflexão" favorece a seleção de assuntos que sirvam ao 
interesse de determinada comunidade, escolhidos apenas após eleição das problemáticas locais; (3) a "realidade" beneficia a opção por temas que possam ser modelados por meio de uma situação real (...); (4) a "responsabilidade" privilegia a prioridade de conteúdos matemáticos que possam ser utilizados para analisar, comparar, estimar e resolver problemas sociais(...); (5) a "recursão" propõe que os conteúdos devem ser dispostos de maneira que possam ser retomados à medida que os estudantes avancem; (6) as "relações" estabelecem preocupações ao organizarmos um currículo como a gestão do tempo e reflexão sobre problemáticas comuns a todos por meio de projetos (...); (7) o "rigor" está ligado a procedimentos, avaliações e à interpretação de resultados inseridos em um novo contexto ligado à indeterminância e à interpretação; (8) a "ressignificação" dá à História da Matemática sua devida importância em uma proposta curricular como articuladora e esclarecedora do processo pelo qual o conhecimento foi construído.

Os oito R's construídos em Silva (2009) contemplam o que o pesquisador chama de "práxis da incerteza" como uma possível abordagem híbrida, buscando a integração de aspectos relevantes das teorias críticas e pós-moderna:

Para as teorias críticas parece haver uma espécie de "estado idealizado das coisas e das pessoas", o qual pode ser obtido por intermédio de uma ação reflexiva (práxis). Para os teóricos pós-modernos, a mudança é um processo constante, envolvendo construção e desconstrução. Bem e mal, opressor e oprimido não são distinguidos claramente como nas concepções críticas (Silva, 2013, p. 219).

Corrobora-se o pesquisador ao acrescentar que não faz sentido estabelecer esses binarismos e que o conceito de práxis da incerteza configura-se como um caminho promissor para o avanço do carente campo de pesquisas sobre currículos de Matemática.

As ideias de Bishop (1999) foram adotadas para verificar como os conteúdos e habilidades listados para os Anos Finais do Ensino Fundamental e na BNCC destacam princípios de seleção e questionamentos sobre as competências matemáticas básicas necessárias para formação do cidadão na contemporaneidade. Elas estão intimamente conectadas aos princípios de seleção e organização dos conteúdos com base nos critérios de Doll (1997) e Silva (2009), uma vez que a identificação dos R's auxilia na compreensão de como gravitam tais competências nas reformas curriculares em uma visão pós-moderna.

A partir da análise das competências matemáticas básicas e dos R's na BNCC, os resultados serão verificados à luz das perspectivas do documento preliminar elaborado pela Organização para a Cooperação e Desenvolvimento Econômico (OCDE) para análise de reformas curriculares mundiais. $\mathrm{O}$ intuito é caracterizar tendências e nortear o ensino das gerações futuras. O projeto "Futuro da Educação e Habilidades 2030" visa ajudar os países a encontrar respostas para identificar conhecimentos, habilidades, atitudes e valores que são necessários para que os estudantes prosperem e moldem seu mundo, bem como maneiras que os sistemas educativos possam efetivamente desenvolvê-los, com foco em:

Tecnologias que ainda não foram inventadas, e resolver problemas sociais que ainda não tenham sido antecipados. A educação pode equipar os alunos com a agência, as competências e sentido de propósito para moldar suas próprias vidas e contribuir para as dos outros. Assim sendo, a mudança é iminente (OCDE, 2018b, p. 1).

O projeto Mathematics Curriculum Document Analysis (MCDA) se propõe a investigar até que ponto os países incorporam perspectivas amplas sobre Alfabetização Matemática e habilidades do século XXI em seu atual currículo, utilizando um quadro desenvolvido em conjunto com o PISA 2021, que criou o Centro para Redesign do Currículo (CRC, 2016).

A Educação 2030 visa conceder suporte aos países na abordagem de desafios comuns de implementação de currículos e na identificação de fatores críticos de sucesso. A vertente 1 do projeto refere-se à elaboração de um quadro de aprendizagem para a Matemática 2030. A vertente 2 consiste na Análise de Programas Curriculares Internacionais, visando construir uma base de conhecimento que permitirá aos países tornarem os processos de design de currículo mais sistemáticos, isto é, apoiar a aprendizagem entre pares internacionais e debates baseados em evidências entre partes interessadas.

Nesse sentido, foram adotadas como categorias analíticas parte do quadro da versão não definitiva do documento elaborado na vertente 1 do projeto MCDA da OCDE para a análise das perspectivas das habilidades da BNCC. No quadro, são apresentados fundamentos para o desenvolvimento de competências consideradas relevantes para a Matemática 2030 .

\section{Metodologia}

No presente artigo, foi realizada uma pesquisa qualitativa com análise documental considerando como único documento a versão final da BNCC para os Anais Finais do Ensino Fundamental. Segundo Borba e Araújo (2013, p.25), pesquisas que adotam essa metodologia:

[...] fornecem informações mais descritivas, que primam pelo significado dado às ações. No âmbito da abordagem qualitativa, diversos métodos são utilizados de forma a se aproximar da realidade social, sendo o método da pesquisa documental aquele que busca compreendê-la de forma indireta por meio da análise dos inúmeros tipos de documentos produzidos pelo homem.

Sharma (2013) ainda acrescenta que "os documentos fornecem evidências de atividades autênticas ou reais realizadas em organizações sociais e de pensamento humano" (p. 3). Sendo assim, serão realizadas análises considerando princípios para a seleção de competências matemáticas básicas na BNCC referentes aos componentes simbólico, social e cultural e os oito R's propostos por Doll e Silva (2009), referentes à seleção dos conteúdos (riqueza, reflexão, realidade e responsabilidade) e à organização curricular 
(recursão, relações, rigor e ressignificação).

Os referenciais foram adotados para análise da prescrição da BNCC para os Anos Finais Ensino Fundamental conectando-os com a discussão do documento preliminar do Projeto Matemática 2030 da OCDE, na tentativa de inferir possíveis impactos relativos à implementação e visando reflexões sobre a reforma curricular em Matemática no país.

\section{Buscando um Caminho para a Seleção de Competências Matemáticas na BNCC}

A BNCC para o Ensino Fundamental (Anos Iniciais e Anos Finais) destaca o dever e compromisso com o desenvolvimento do letramento matemático. No documento enfatiza-se que os processos matemáticos de resolução de problemas, de investigação, de desenvolvimento de projetos e de modelagem podem ser citados como formas privilegiadas da atividade matemática. Esse é o motivo pelo qual são, ao mesmo tempo, objeto e estratégia para a aprendizagem ao longo de todo o Ensino Fundamental. "Esses processos de aprendizagem são potencialmente ricos para o desenvolvimento de competências fundamentais para o letramento matemático (raciocínio, representação, comunicação e argumentação)" (Brasil, 2017, p.264). Essa perspectiva na apresentação da BNCC remete-se ao componente social (Bishop, 1999), uma vez que aborda o desenvolvimento de projetos sugerindo pensar a aprendizagem e a maneira que se utilizam as ideias matemáticas em situações sociais, e ao critério realidade (Silva, 2009) ao associar tais projetos à modelagem.

Considerando esses pressupostos, e em articulação com as competências gerais da Educação Básica, no documento é apontado que a área de Matemática e, por consequência, o componente curricular de Matemática, devem garantir aos alunos o desenvolvimento de competências específicas que precisam destacar, nessa etapa de ensino:

[...] a importância da comunicação em linguagem matemática com o uso da linguagem simbólica, da representação e da argumentação. Além dos diferentes recursos didáticos e materiais, como malhas quadriculadas, ábacos, jogos, calculadoras, planilhas eletrônicas e softwares de geometria dinâmica, é importante incluir a história da Matemática como recurso que pode despertar interesse e representar um contexto significativo para aprender e ensinar Matemática. Entretanto, esses recursos e materiais precisam estar integrados a situações que propiciem a reflexão, contribuindo para a sistematização e a formalização dos conceitos matemáticos. Cumpre também considerar que, para a aprendizagem de certo conceito ou procedimento, é fundamental haver um contexto significativo para os alunos, não necessariamente do cotidiano, mas também de outras áreas do conhecimento e da própria história da Matemática (Brasil, 2017, p. 296).

A competência específica para o Ensino Fundamental remete-se ao componente simbólico (Bishop, 1999), pois destaca as ferramentas matemáticas essenciais em qualquer cultura para a aprendizagem (recursos) em contextos significativos para o aluno. Tal prescrição também se remete ao critério de organização curricular riqueza ao privilegiar a escolha de conteúdos que mostrem quão rica é a própria matemática e como a relação teoria-prática pode ser efetivada eficientemente. O critério de organização ressignificação (Silva, 2009) foi identificado na apresentação das competências ao destacar a História da Matemática para significar conceitos construídos em diferentes contextos:

Além disso, nessa fase final do Ensino Fundamental, é importante iniciar os alunos, gradativamente, na compreensão, análise e avaliação da argumentação matemática. Isso envolve a leitura de textos matemáticos e o desenvolvimento do senso crítico em relação à argumentação neles utilizada (Brasil, 2017, p. 297).

Nesse trecho da apresentação da área para os Anos Finais do Ensino Fundamental, é destacado o critério de organização curricular rigor (Silva, 2009) ao sinalizar a importância da avaliação e do senso crítico em processos que envolvam a argumentação matemática.

Especificamente para os Anos Finais do Ensino Fundamental $\left(6 .^{\circ}\right.$ ao $9 .^{\circ}$ ano), foi realizada uma busca por trechos do documento a partir do questionamento sobre as competências matemáticas básicas de Bishop (1999) necessárias para a formação do aluno em nossa contemporaneidade. Identificaram-se, nas unidades temáticas, objetos de conhecimento e habilidades requeridas para cada ano, indícios da presença dos componentes simbólico, social e cultural propostos pelo teórico. Eles foram relacionados aos critérios de seleção de conteúdos (R's) propostos por Doll e Silva (2009). Apresenta-se, no Quadro 1, a relação dos componentes e critérios evidenciados na BNCC.

Continua...

Quadro 1 - Componentes e critérios de organização e seleção de conteúdos identificados na BNCC Anos Finais do Ensino Fundamental.

\begin{tabular}{|c|c|c|c|c|c|}
\hline Ano & $\begin{array}{c}\text { Unidade } \\
\text { Temática }\end{array}$ & $\begin{array}{c}\text { Objetos de } \\
\text { Conhecimento }\end{array}$ & Habilidade(s) & Componentes & Critérios (R's) \\
\hline 7..$^{\circ}$ & $\begin{array}{l}\text { Probabilidade e } \\
\text { Estatística }\end{array}$ & $\begin{array}{l}\text { Pesquisa amostral e } \\
\text { pesquisa censitária. } \\
\text { Planejamento de } \\
\text { pesquisa, coleta e } \\
\text { organização dos } \\
\text { dados, construção } \\
\text { de tabelas e gráficos } \\
\text { e interpretação das } \\
\text { informações. }\end{array}$ & $\begin{array}{l}\text { (EF07MA36) Planejar e realizar } \\
\text { pesquisa envolvendo tema da realidade } \\
\text { social, identificando a necessidade de } \\
\text { ser censitária ou de usar amostra, e } \\
\text { interpretar os dados para comunicá-los } \\
\text { por meio de relatório escrito, tabelas } \\
\text { e gráficos, com o apoio de planilhas } \\
\text { eletrônicas (p. 309). }\end{array}$ & Social & $\begin{array}{l}\text { Realidade e } \\
\text { Responsabilidade }\end{array}$ \\
\hline
\end{tabular}


Continuação...

\begin{tabular}{|c|c|c|c|c|c|}
\hline Ano & $\begin{array}{l}\text { Unidade } \\
\text { Temática }\end{array}$ & $\begin{array}{c}\text { Objetos de } \\
\text { Conhecimento }\end{array}$ & Habilidade(s) & Componentes & Critérios (R's) \\
\hline $7 .^{\circ}$ & Álgebra & $\begin{array}{l}\text { Linguagem } \\
\text { algébrica: variável e } \\
\text { incógnita. }\end{array}$ & $\begin{array}{l}\text { (EF07MA13) Compreender a ideia } \\
\text { de variável, representada por letra ou } \\
\text { símbolo, para expressar relação entre } \\
\text { duas grandezas, diferenciando-a da ideia } \\
\text { de incógnita. } \\
\text { (EF07MA14) Classificar sequências } \\
\text { em recursivas e não recursivas, } \\
\text { reconhecendo que o conceito de recursão } \\
\text { está presente não apenas na matemática, } \\
\text { mas também nas artes e na literatura. } \\
\text { (EF07MA15) Utilizar a simbologia } \\
\text { algébrica para expressar regularidades } \\
\text { encontradas em sequências numéricas } \\
\text { (p. 305). }\end{array}$ & Simbólico & Realidade \\
\hline \multirow{2}{*}{$9 .^{\circ}$} & $\begin{array}{l}\text { Probabilidade e } \\
\text { Estatística }\end{array}$ & $\begin{array}{l}\text { Planejamento } \\
\text { e execução de } \\
\text { pesquisa amostral } \\
\text { e apresentação de } \\
\text { relatório. }\end{array}$ & $\begin{array}{l}\text { (EF09MA23) Planejar e executar } \\
\text { pesquisa amostral envolvendo tema } \\
\text { da realidade social e comunicar os } \\
\text { resultados por meio de relatório } \\
\text { contendo avaliação de medidas de } \\
\text { tendência central e da amplitude, tabelas } \\
\text { e gráficos adequados, construídos com o } \\
\text { apoio de planilhas eletrônicas (p. 317). }\end{array}$ & Social & $\begin{array}{l}\text { Rigor e } \\
\text { Responsabilidade }\end{array}$ \\
\hline & Álgebra & $\begin{array}{l}\text { Grandezas } \\
\text { diretamente } \\
\text { proporcionais } \\
\text { e grandezas } \\
\text { inversamente } \\
\text { proporcionais. }\end{array}$ & $\begin{array}{l}\text { (EF09MA08) Resolver e elaborar } \\
\text { problemas que envolvam relações de } \\
\text { proporcionalidade direta e inversa } \\
\text { entre duas ou mais grandezas, inclusive } \\
\text { escalas, divisão em partes proporcionais } \\
\text { e taxa de variação, em contextos } \\
\text { socioculturais, ambientais e de outras } \\
\text { áreas (p. 315). }\end{array}$ & $\begin{array}{l}\text { Social } \\
\text { Cultural }\end{array}$ & $\begin{array}{l}\text { Riqueza, Reflexão, } \\
\text { Realidade, } \\
\text { Responsabilidade e } \\
\text { Rigor. }\end{array}$ \\
\hline
\end{tabular}

Fonte: Dados da pesquisa.

Conforme o Quadro 1 na prescrição da BNCC para os Anos Finais do Ensino Fundamental, foram constatadas a ausência dos componentes propostos por Bishop (1999) nos $6 .^{\circ}$ e $8 .^{\circ}$ anos e a presença do componente cultural apenas no $9 .^{\circ}$ ano. Isso representa lacunas na proposta em relação às competências específicas anunciadas pelo documento. A Base prescreve que, nesta etapa, o aluno deverá enfrentar situações-problemas em múltiplos contextos, utilizando diferentes registros e linguagens, e "desenvolver e/ou discutir projetos que abordem, sobretudo, questões de urgência social, com base em princípios éticos, democráticos, sustentáveis e solidários, valorizando a diversidade de opiniões de indivíduos e de grupos sociais, sem preconceitos de qualquer natureza" (Brasil, 2017, p. 265).

Essas dimensões estão relacionadas tanto ao processo de ensino e aprendizagem quanto à organização curricular da Matemática escolar e a ausência delas pode trazer implicações no desenvolvimento de competências básicas listadas pela BNCC.

$\mathrm{Na}$ unidade Probabilidade e Estatística do 7. ${ }^{\circ}$ ano, a habilidade requerida pressupõe planejamento e realização de pesquisas envolvendo tema da realidade social, identificando tipologia de amostras e interpretando os dados para comunicálos. Tal prescrição remete-se ao componente social, uma vez que propõe ao desenvolvimento curricular pensar em como utilizar ferramentas e ideias matemáticas num contexto social.
Os critérios de seleção realidade, ao tratar de pesquisas que podem ser modeladas a partir de uma situação real, e responsabilidade, por priorizar análise de dados que podem impactar a sociedade, também foram contemplados.

$\mathrm{Na}$ Álgebra, as habilidades referem-se ao componente simbólico, uma vez que requerem situações problemas que devam ser exploradas pelos seus significados, lógica, conexões e regularidades, e que possam ser generalizadas para outros contextos ou áreas. Quanto ao critério, refere-se à realidade ao apontar que, em situações reais, a linguagem algébrica permite descrever, representar e apresentar resultados com precisão e argumentar sobre suas conjecturas, estabelecendo relações entre ela e diferentes representações.

No 9. ${ }^{\circ}$ ano, para a unidade Probabilidade e Estatística, foi identificado o componente social. Ele sugere o planejamento de projeto de pesquisa que permita o desenvolvimento de consciência crítica a partir de ferramentas de organização e análise de dados estatísticos de temas que deverão ser escolhidos dentro um contexto social. No que tange à organização curricular, identificou-se o critério rigor, pois a pesquisa amostral está intrínseca a procedimentos, avaliações e interpretações que considerarão variáveis sociais. O critério de seleção responsabilidade destaca-se, uma vez que pesquisas estatísticas permitem análise, comparação e estimativas que podem colaborar com a resolução de questões sociais.

Para a Álgebra, a habilidade listada visa ampliar o repertório 
do aluno em relação aos conhecimentos imprescindíveis em qualquer cultura, remetendo-se aos componentes cultural e social, ao enfatizar que ideias fundamentais sobre o conhecimento matemático em um contexto social e cultural podem trazer perspectivas de trabalho com projetos sobre a sociedade do passado, a atual e a do futuro.

Em relação aos critérios de seleção de conteúdos, identificou-se: a riqueza, pois relações de proporcionalidade e taxas de variação permitem perceber quão rica é a Matemática; a reflexão, por favorecer a seleção de assuntos em contextos socioculturais, ambientais e outros; a realidade, por se tratar de conhecimentos que permitem o tratamento de situações reais; e a responsabilidade, por serem utilizados para analisar, comparar, estimar e resolver problemas sociais. Sobre o critério organizacional rigor, a prescrição sugere o trabalho com taxas de variação, permitindo a modelagem em contextos ligados à indeterminância e à interpretação, inclusive em processos de tomada de decisão e previsões futuras.

No esboço do quadro de Aprendizagem para Matemática 2030 (OCDE, versão preliminar, 2018a), os conteúdos listados para análise nas prescrições dos programas na unidade Álgebra foram relacionados ao item Mudanças de Quadro:1. Fundamentos de Álgebra: Taxas e proporções; Relações Proporcionais, Álgebra Inicial, Expressões $e$ Equações lineares simples e Álgebra e 2. Funções. Os conteúdos considerados para análise na unidade Probabilidade Estatística foram os relacionados à sessão Dados e incerteza: Representação de dados, Variância e Distribuição Estatísticas, Inferência estatística incluindo amostras aleatórias, Distribuições de amostragem, Teste de hipóteses e Probabilidade.

Esses objetos de conhecimento presentes na BNCC foram relacionados ao tópico Raciocínio Matemático - Conceitos Fundamentais, que trata de temáticas do projeto, como: Sistema numérico e suas propriedades algébricas, Matemática como um sistema baseado em abstrações e representação simbólica, A estrutura da matemática e suas regularidades, Relações funcionais entre quantidades, Modelagem matemática como uma lente para o mundo real e a Variância como o coração da estatística. Essas ênfases já haviam sido levantadas por Artigue (2018) em seus estudos sobre reformas curriculares.

As habilidades, atitudes e valores relevantes para a Matemática, em alinhamento com o quadro da OCDE Aprendizagem 2030 e o exercício Curriculum Mapeamento de Conteúdo, indicam como conceitos-chave a iniciativa/ação estudantil e as competências, atitudes e valores consideradas pelo Projeto Matemática 2030 (Quadro 2), inerentes às competências matemáticas básicas (Bishop, 1999), organização e seleção de conteúdos (Silva, 2009).
Quadro 2 - Quadro preliminar - Conceitos-chave: habilidades, atitudes e valores para a Matemática 2030

\begin{tabular}{|c|c|}
\hline $\begin{array}{l}\text { Solução de } \\
\text { Problemas }\end{array}$ & $\begin{array}{l}\text { A resolução de problemas refere-se à } \\
\text { capacidade de um indivíduo se envolver em } \\
\text { processamento cognitivo para compreender } \\
\text { e resolver situações em que um método ou } \\
\text { solução não é imediatamente óbvio (OCDE, } \\
\text { 2016). } \\
\text { A resolução de problemas é multifacetada e } \\
\text { multidimensional, e pode incluir uma variedade } \\
\text { de formas, incluindo solução individual, } \\
\text { colaborativa e criativa de problemas. }\end{array}$ \\
\hline $\begin{array}{l}\text { Pensamento } \\
\text { crítico }\end{array}$ & $\begin{array}{l}\text { O pensamento crítico é definido como } \\
\text { questionamento e avaliação de ideias e } \\
\text { soluções (OCDE, 2016). O pensamento crítico } \\
\text { é uma habilidade cognitiva de ordem superior } \\
\text { e inclui raciocínio indutivo e dedutivo, fazendo } \\
\text { análises, inferências e avaliações corretas } \\
\text { (Facione et al., 1995; Liu, Frankel, \& Partlow, } \\
\text { 2012). }\end{array}$ \\
\hline Reflexão & $\begin{array}{l}\text { A reflexão envolve a vinculação de uma } \\
\text { experiência atual a aprendizados anteriores } \\
\text { (OCDE, 2016). }\end{array}$ \\
\hline Comunicação & $\begin{array}{l}\text { A comunicação exige uma relação entre duas } \\
\text { ou mais pessoas envolvendo a transferência } \\
\text { de informações (mensagens, ideias, } \\
\text { conhecimentos, estratégias, etc.) (OCDE, } \\
\text { 2003). }\end{array}$ \\
\hline
\end{tabular}

Fonte: Documento Preliminar (OCDE, 2018a, p. 8).

Os processos matemáticos de resolução de problemas, de investigação, de desenvolvimento de projetos e de modelagem são configurados na BNCC como "potencialmente ricos para o desenvolvimento de competências fundamentais para o letramento matemático (raciocínio, representação, comunicação e argumentação)" (Brasil, 2017, p.222). São perspectivados pelo quadro de aprendizagem da OCDE como um processamento cognitivo para compreensão de problemas, configurando-se um processo multifacetado e multidimensional, que envolve a comunicação e o trabalho criativo.

Os critérios de organização curricular ressignificação e rigor (Silva, 2009) foram identificados na apresentação de competências específicas ao enfatizarem a importância de "iniciar os alunos, gradativamente, na compreensão, análise e avaliação da argumentação matemática, destacando a necessidade do desenvolvimento do senso crítico na argumentação utilizada, assim como na descrição do Pensamento Crítico" (OCDE, 2018a, p. 2).

O critério reflexão, evidenciado no 9. ${ }^{\circ}$ ano - Álgebra - Grandezas diretamente proporcionais e grandezas inversamente proporcionais - , associadas aos componentes social e cultural (Bishop, 1999), por favorecerem a seleção de assuntos em contextos socioculturais, são complementadas pela ênfase dada ao quadro de aprendizagem da OCDE para o foco nas experiências atuais e aprendizagens anteriores (OCDE, 2016) dos alunos no enfrentamento de problemas dessa natureza.

Relativas às unidades temáticas relacionadas à análise da BNCC, é trazida, no quadro do Projeto Matemática 2030 
(Quadro 3), a perspectiva associada aos resultados da análise anterior.

Quadro 3 - Fundamentos para o desenvolvimento e competências relevantes para a Matemática 2030

\begin{tabular}{|c|c|}
\hline $\begin{array}{l}\text { Alfabetização } \\
\text { de Dados }\end{array}$ & $\begin{array}{l}\text { Alunos com conhecimento de dados adquirem } \\
\text { informações significativas, criam e comunicam } \\
\text { usando dados baseados em compreensão e } \\
\text { habilidades matemáticas, particularmente, } \\
\text { em relação à estatística. A alfabetização } \\
\text { em dados inclui pensar criticamente sobre } \\
\text { as informações apresentadas nos formatos } \\
\text { estatísticos para analisar os dados e determinar } \\
\text { a precisão das informações e interpretações } \\
\text { feitas com base nos dados. }\end{array}$ \\
\hline
\end{tabular}

Fonte: Documento Preliminar (OCDE, 2018a, p. 9).

Nos 7. ${ }^{\circ}$ e 9..$^{\circ}$ anos, unidade Probabilidade e Estatística, foram evidenciados o componente social de Bishop (1999), os critérios realidade e responsabilidade de seleção de conteúdos e rigor referente à organização curricular de Silva (2009). Em síntese, enfatizam o planejamento e execução de pesquisas, identificando a necessidade da análise de amostras por meio da interpretação e avaliação de dados para comunicá-los. A Alfabetização de Dados, na perspectiva do Projeto Matemática 2030 (OCDE, 2018a), acrescenta o pensamento crítico como uma competência valiosa para determinar a precisão das análises estatísticas.

\section{Considerações Finais}

No artigo em tela, foram trazidas contribuições teóricas contemporâneas no âmbito do campo de pesquisa sobre currículo. Argumenta-se a carência de enfoques investigativos sobre a temática na Educação Matemática, alertando a necessidade de maiores abordagens de estudos nessa direção.

Constatou-se na BNCC para os Anos Finais do Ensino Fundamental, a presença dos componentes social, simbólico e cultural atrelados aos objetos de conhecimento e suas respectivas habilidades, frutos do questionamento sobre o desenvolvimento de competências matemáticas básicas necessárias para formação do aluno brasileiro atualmente.

Constatou-se também, a presença dos critérios de seleção de conteúdos e de organização curricular pressupõem nas unidades Álgebra e Probabilidade e Estatística (Artigue, 2018), que podem vir a promover uma visão multicultural para o currículo ao relacionar os objetos de conhecimento, dando ao estudante a oportunidade de perceber o sentido dos conteúdos e fazer seu uso social, desenvolvendo sua cidadania. Tais perspectivas não foram identificadas nas unidades temáticas Números e Operações e Geometria.

Por meio das análises, foi possível relacionar a perspectiva de letramento matemático da BNCC com os componentes social e cultural (Bishop, 1999), os critérios reflexão e rigor (Silva, 2009) e Resolução de Problemas, Pensamento Crítico, Reflexão e Comunicação do quadro de aprendizagem para a Matemática 2030 (OCDE, 2018a).
Na unidade Probabilidade e Estatística da BNCC, o componente social (Bishop, 1999), atrelado aos critérios realidade, responsabilidade e rigor (Silva, 2009), com os Fundamentos de Desenvolvimento e Competências de Alfabetização de Dados para a Matemática 2030 (OCDE, 2018a), suscitou a necessidade do pensamento crítico como competência imprescindível para a precisão das análises estatísticas inferidas pelos alunos.

A hibridização dos componentes, critérios de seleção de conteúdos e organização curricular, além do quadro preliminar em discussão para a análise de documentos do Projeto Matemática (2030), configuram-se como caminhos e referenciais relevantes para a análise das prescrições. Apresentam-se, também, como uma forma de vigilância e resistência a programas que desconsideram como pontos-chave questões de cidadania e acesso ao conhecimento matemático por meio de questões de cunho social e cultural, focando na organização e seleção de conteúdos e competências para atendimento de demandas de mão de obra para as sociedades atual e futura (Baeten \& Schneider, 2012; Clements et al., 2013; Volmink, 2018; Artigue, 2018).

No quadro preliminar do Projeto Matemática 2030, adotado na última etapa de hibridização, foram trazidas categorias importantes para o estabelecimento de critérios para investigação de currículos com vistas a apontar tendências nas reformas dos países. No entanto, alerta-se que o projeto é gerenciado pela OCDE, entidade relevante, com interesses na implementação da BNCC. Isso indica ao mundo empresarial quais países estão cumprindo orientações em áreas, como Educação e Economia, sinalizando locais para investimentos de empresas privadas que almejam mão de obra qualificada segundo seus padrões estabelecidos.

\section{Referências}

Artigue. M. (2018). Implementing Curricular Reforms: A Systemic Challenge. In: ICMI Study 24, Conference Proceedings. School Mathematics Curriculum Reforms: Challenges, Changes and Opportunities. November 25-30, 2018, Tsukuba, Japan, University of Tsukuba. pp. 43-52.

Baeten, E., \& Schneider, M. (2012). Le paradigme des compétences en communauté française de Belgique, et plus particulièrement dans l'enseignement secondaire. In J.-L. Dorier, \& S. Coutat (Eds.). Actes du Colloque (pp.53-65). EMF.

Bishop, A.J. (1999). Enculturación matemática: la educación matemática desde una perspectiva cultural. Buenos Aires: Paidós.

Borba, M.C., Araújo, J.L. (2013). Pesquisa qualitativa em Educação Matemática: notas introdutórias. In: M. C. Borba, \& J. L. Araújo (Org.). Pesquisa Qualitativa em Educação Matemática. Belo Horizonte: Authentic.

Brasil (2017). Base Nacional Comum Curricular (BNCC). Ensino Fundamental: Anos Finais. Recuperado de http:// basenacionalcomum.mec.gov.br/images/BNCC_publicacao. pdf.

Clements, M.A., Keitel, C., Bishop, A. J., Kilpatrick, J., \& Leung, F. K. (2013). From the few to the many: Historical perspectives 
on who should learn mathematics. In M. A. Clements, A. J. Bishop, C. Keitel, J. Kilpatrick, F. Leung. (Eds.). Third international handbook of mathematics education (pp.7-40). New York, NY: Springer.

Dias, M.O. (2016). Tendências em Educação Matemática: percursos curriculares brasileiros e paraguaios. Curitiba: Appris.

Doll, W. E., Jr. (1997). A post-modern perspective on curriculum. New York: Teachers College Press.

OECD (2016), Trends Shaping Education 2016. Paris:, OECD. doi: http://dx.doi.org/10.1787/trends_edu-2016-en.

Organização para a Cooperação e Desenvolvimento Econômico (2018a). Projeto Matemática 2030. Paris, França.

Organização para a Cooperação e Desenvolvimento Econômico (2018b). The Future of Education and Skills Education 2030. Paris, France. Recuperado de https://www.oecd. org/education/2030/E2030\%20Position\%20Paper\%20 (05.04.2018).pdf
Sacristán, J. G. (2000). O Currículo: uma reflexão sobre a prática. Porto Alegre: Artmed.

Sharma, S. (2013). Qualitative approaches in mathematics education research: challenges and possible solutions. Education Journal, 2(2): 50-57. doi: 10.11648/j. edu. 20130202.14

Silva, M. A. (2009). Currículos de Matemática no Ensino Médio: em busca de critérios para escolha e organização de conteúdos. (Tese de Doutorado em Educação Matemática Pontifícia Universidade Católica de São Paulo).

Silva, M. A. (2013). Contribuições Contemporâneas para as Discussões Curriculares em Educação Matemática: a teoria crítica pós-moderna. Alexandria - Revista de Educação em Ciência e Tecnologia, 6(1), 205-233.

Volmink, J. (2018). School Mathematics Reform South Africa: a Curriculum for all and by all? In: ICMI Study 24, Conference Proceedings. School Mathematics Curriculum Reforms: Challenges, Changes and Opportunities (pp.101-108). Tsukuba, Japan: University of Tsukuba. 